\title{
Genotype and phenotype analysis of a cohort of patients with congenital hyperinsulinism based on DOPA-PET CT scanning
}

\author{
Jinwen $\mathrm{Ni}^{1}$ - Jingjie $\mathrm{Ge}^{2} \cdot$ Miaoying Zhang ${ }^{1} \cdot \mathrm{Khalid} \mathrm{Hussain}^{3} \cdot$ Yihui Guan $^{2} \cdot$ Ruoqian Cheng $^{1} \cdot \mathrm{Li} \mathrm{Xi}^{1}$ • \\ Zhangqian Zheng ${ }^{1} \cdot$ Shuhua Ren ${ }^{2} \cdot$ Feihong Luo $^{1}$
}

Received: 5 February 2019 / Revised: 4 June 2019 / Accepted: 5 June 2019 / Published online: 19 June 2019

(C) The Author(s) 2019

\begin{abstract}
Congenital hyperinsulinism (CHI) is a clinically, genetically, and morphologically heterogeneous disorder. ${ }^{18} \mathrm{~F}$ DOPA-PET CT scanning greatly improves its clinical outcome. Here, we presented the first Chinese ${ }^{18} \mathrm{~F}$ DOPA-PET CT scanning-based CHI cohort highlighting the variable ethic clinical phenotypes and genotypes. Fifty CHI patients were recruited. Median age at presentation was 2 days. Median fasting time was $2 \mathrm{~h}$. Mean insulin level was $25.6 \mu \mathrm{IU} / \mathrm{ml}$. Fifty-two percent of patients were diazoxide-unresponsive with significantly shorter fasting tolerance time and higher serum insulin level compared with the responsive patients. Seventy-four percent of patients experienced at least one adverse drug reaction. Tremendously increased focal lesions $(32 \%)$ were detected and $75 \%$ of them were cured through surgery. Thirty-one nucleotide sequence changes were identified in $48 \%$ patients. Four novel variants (Q608X, Q1347X, Q289X, F1489S) in ABCC8 gene and 2 novel variants (G132A, V138E) in KCNJ11 gene were detected. Of the variants, $87.1 \%$ harbored in $A B C C$ and $K C N J 11$ genes. T1042Qfs*75 in $A B C C 8$ gene was the most common mutation.

Conclusion: Highly increased portion of focal lesion was presented in Chinese CHI patients compared with that of the previous reports. Intolerance to diazoxide was much more evident in Chinese or East Asian than other populations. Certain hotspot mutations harbored in Chinese CHI patients.
\end{abstract}

What is Known:

- ${ }^{18}$ F DOPA-PET CT scanning can provide informative guidance for surgical procedure when medical therapy is not well responded in CHI patients.

What is New:

- Intolerance to diazoxide is much more evident in Chinese and East Asian CHI patients compared with the other ethnic populations.

- Novel mutations were detected in ABCC8 and KCNJ11 gene. Hotspot mutations such as T1042Qfs*75, I1511K, E501K, G111R in ABCC8 gene, and R34H in KCNJ11 gene are predominantly responsible for Chinese CHI patients.

Communicated by Peter de Winter

Feihong Luo

luofh@fudan.edu.cn

Jinwen Ni

16111240022@fudan.edu.cn

Jingjie Ge

lovejingjie@126.com

Miaoying Zhang

miaoyingzhang@126.com

Khalid Hussain

khussain@sidra.orgt

Yihui Guan

guanyihui@hotmail.com

Ruoqian Cheng

chengrq78@163.com
Li Xi

drxili@163.com

Zhangqian Zheng

dr_zhengzhangqian@126.com

Shuhua Ren

karen96_ren@126.com

1 Department of Endocrinology and Inborn Metabolic Diseases, Children's Hospital of Fudan University, 399 Wanyuan Road, Shanghai 201102, China

2 PET CT Center, Division of Nuclear Medicine, Huashan Hospital, Fudan University, 518 East Wuzhong Road, Shanghai 200235, China

3 Department of Pediatrics, Division of Endocrinology, Sidra Medicine OPC, C6-340 PO Box 26999, Al Luqta Street Education City North Campus, Doha, Qatar 
Keywords Congenital hyperinsulinism $\cdot$ Hypoglycemia $\cdot$ Hyperinsulinemia $\cdot$ Mutation $\cdot$ Genetic association studies

\author{
Abbreviations \\ CHI Congenital hyperinsulinism \\ ${ }^{18}$ F-DOPA Fluorine-18-labeled L-dihydroxyphenylalanine \\ PET Positron emission tomography \\ ADR Adverse drug reaction
}

\section{Introduction}

Congenital hyperinsulinism (CHI) is the most common cause of persistent hypoglycemia in newborns and infants which usually presents with intractable severe hypoglycemia [11, 14]. An early diagnosis and appropriate management of CHI is mandatory to avoid subsequent brain damage and neurologic disabilities [11, 14]. Single or combined drugs' therapy of $\mathrm{CHI}$ is the first choice; however, medically unresponsive is frequent. Adverse drug reaction could also lead to therapy suspension. Then the management of the disease was largely dependent on its pancreas histological lesion subtype [9].

There are two major histological subtypes of CHI, diffuse and focal forms, which are clinically identical but differ in histology, underlying genetic mechanisms and management regiments [2]. Diffuse form exhibits islet cell hyperplasia involving the entire pancreas while focal form represents a localized area of islet cell adenomatosis surrounded by an otherwise normal pancreas. However, both of the two forms are unable to be identified from each other using biochemical methods [11]. If medical therapy is unresponsive, CHI patients with diffuse form require a subtotal (80-94\% removal of the gland) or near-total (95\%) pancreatic resection to achieve euglycemia [5]. But patients with focal form can be cured completely through a limited pancreatic resection of the focal lesion [1]. Therefore, the pre-operative distinction between the diffuse and focal form is vitally important.

The routine imaging techniques, such as CT or MRI, have limited values in distinguishing the diffuse and focal forms of CHI. Pancreatic venous sampling or the pancreatic arterial calcium stimulation test in pediatric period is highly invasive, and not so accurate [24]. Genetic analysis of CHI-related genes could be informative, for example, paternal germline mutations in $A B C C 8$ or $K C N J 11$ are associated with the focal form of $\mathrm{CHI}$ whereas biallelic recessive mutations are associated with the diffuse form [3, 11]. However, no CHI-related mutations can be found in about $50 \%$ of all cases worldwide $[4,15,21,23,28]$. Recently, an accurate and sensitive technique, positron emission tomography (PET) using fluorine18-labeled L-dihydroxyphenylalanine $\left({ }^{18} \mathrm{~F}\right.$-DOPA), has been applied in $\mathrm{CHI}$ to help with pre-operative localization of the focal lesion, but mainly in Caucasian populations [12, 20, 22]. Recently, the local ${ }^{18} \mathrm{~F}$-DOPA PET CT imaging successfully applied in the clinical settings [29]. So, in this study, we further explore the genotype-phenotype correlations and clinical prognosis in a cohort of Chinese $\mathrm{CHI}$ patients after ${ }^{18} \mathrm{~F}$-DOPA PET CT scanning.

\section{Patients and methods}

\section{Patients}

Altogether, 50 Chinese CHI patients were admitted into the study. A controlled fasting test was done on the patients. The diagnosis of CHI was based on the following criteria: (1) consistently detectable insulin/C-peptide with blood glucose level $<2.6 \mathrm{mmol} / 1(46.8 \mathrm{mg} / \mathrm{dL})$; (2) glucose infusion rate greater than $8 \mathrm{mg} / \mathrm{kg}$ per minute to maintain blood glucose greater than $3 \mathrm{mmol} / 1(54 \mathrm{mg} / \mathrm{dL})$; (3) inappropriate hypoketosis and undetectable/low free fatty acids during hypoglycemia; (4) a positive glycemic response to glucagon. A 5-day trial of diazoxide $(5-15 \mathrm{mg} / \mathrm{kg} / \mathrm{d}$ in 3 divided doses) was started after diagnosis. The patients were defined as diazoxide unresponsive if intravenous dextrose could not be weaned or plasma glucose level of $<3.0 \mathrm{mmol} / \mathrm{l}$ during feeding and fasting periods. Diazoxide was discontinued in patients if there were obvious side effects such as gastrointestinal disturbances, edema, water-sodium retention, and congestive heart failure. So in these patients, the responsiveness to diazoxide was not completely known.

\section{${ }^{18}$ F-DOPA-PET CT scan}

The ${ }^{18}$ F-DOPA-PET CT scan was performed in all CHI patients at Huashan Hospital, Fudan University. Under general anesthesia, all the patients were fasted for at least $6 \mathrm{~h}$, received intravenous dextrose infusion to control blood glucose level. Administration of glucagon was suspended 2 days before the procedure. A PET scan of the abdomen was done using a hybrid machine (Siemens BiographTM Truepoint PET/CT, Siemens Healthcare, Erlangen, Germany) 60 min after i.v. administration of ${ }^{18} \mathrm{~F}$-DOPA $(6 \mathrm{MBq} / \mathrm{Kg}) .{ }^{18} \mathrm{~F}$-DOPA was produced by the nucleophilic method and was approved for clinical use in China by the National Medical Products Administration. A contrast-enhanced CT was also sequentially performed. Standard uptake value (SUV) was calculated between the area with the highest uptake and the rest of the pancreas. A SUV ratio $>1.5$ was considered indicative of a focal lesion [13]. 
Histology

Diazoxide-unresponsive patients and patients with focal type identified by ${ }^{18} \mathrm{~F}$ DOPA-PET CT scanning underwent pancreatectomy. The results of PET scan were made available to surgeons to help identify the potential lesion. During surgery, biopsies from the head, body, and tail of the pancreas were examined. Hematoxylin and eosin (H\&E)-stained and immunohistochemical analysis was done to differentiate the histologic form of CHI. The determination of focal versus diffuse lesion was made on the permanent histologic sections by two pathologists who were masked to the results of the PET scan.

\section{Genetic analysis}

Genomic DNA was extracted from peripheral leukocytes of the patients using QIAamp DNA Blood Mini Kit (Qiagen, Hilden, Germany). The protein-coding regions of human ABCC8 (NM_000352.4), KCNJ11 (NM_000525.3), GCK (NM_000162.3), GLUD1 (NM_005271.3), HADH (NM_001184705.2), HNF4A (NM_000457.4), SLC16A1 (NM_003051.3), and UCP2 (NM_003355.2) genes was analyzed using Ion Torrent PGMTM [4]. The variants were validated by direct Sanger sequencing using an automated sequencer (ABI 3130 Genetic Analyzer; Applied Biosystems, Foster City, CA). Human Gene Mutation Database (http:// www.hgmd.cf.ac.uk/ac/index.php), Online Mendelian Inheritance in Man Database (http://www.ncbi.nlm.nih.gov/ omim), Single-Nucleotide Polymorphism Database (dbSNP 137, http://www.ncbi.nlm.nih.gov/snp), and 1000 Genomes Project (http://www.1000genomes.org/) were consulted to evaluate all the filtered variants. Furthermore, the Polymorphism Phenotyping (PolyPhen-2; http://genet-ics. bwh.harvard.edu/pph2), Sorting Intolerant From Tolerant (SIFT; http://sift.jcvi.org), and Mutation Taster (http://www. mutationtaster.org/) were used to test the pathogenicity of all the variants. ESEfinder (http://rulai.cshl.edu/tools/ESE/) was used to detect alterations in exonic splicing enhancers (ESE) due to nucleotide changes. Changes affecting highly conserved positions were generally interpreted as having damaging effects. Related variants were assessed in 50 normal controls.

\section{Statistical analysis}

Data was analyzed using SPSS software version 17.0. Qualitative data are expressed in percentage. Quantitative data were expressed as mean \pm standard deviation. Quantitative data consistent with the homogeneity of variance were analyzed using $t$ test; otherwise, the Wilcoxon rank sum test was used. The statistical significance level was set at 0.05 .

\section{Results}

\section{Clinical background of the $\mathrm{CHI}$ patients}

Among the $50 \mathrm{CHI}$ patients (29 male and 21 female), no remarkable hypoglycemia or diabetes family history was found. The mean birth weight was $4007.6 \pm 645.3 \mathrm{~g}$ for male and $3810 \pm 589.7 \mathrm{~g}$ for female, both of which were above the 90th percentile of the national reference standard. The median age at presentation was 2 days after birth (range, 0 days to 11 years). At diagnosis, the median fasting time were $2 \mathrm{~h}$ (range, 0.3 to $12 \mathrm{~h}$ ). The mean blood glucose was $2.1 \mathrm{mmol} /$ 1 (range, 1.1 to $2.6 \mathrm{mmol} / \mathrm{l}$ ), while the mean insulin level was $25.6 \mu \mathrm{IU} / \mathrm{ml}$ (range, $2.5-156 \mu \mathrm{IU} / \mathrm{ml}$ ). To maintain blood glucose greater than $3 \mathrm{mmol} / 1(54 \mathrm{mg} / \mathrm{dl})$, the mean required glucose infusion rate was $11.3 \mathrm{mg} / \mathrm{kg} \cdot \mathrm{min}$ (range, $8_{-}$ $20 \mathrm{mg} / \mathrm{kg} \cdot \mathrm{min})$. Besides, 20 (40\%) patients needed extra continuous glucagon intravenous infusion in a mean rate of $8.5 \mu \mathrm{g} / \mathrm{kg} \cdot \mathrm{h}(1.6-20 \mu \mathrm{g} / \mathrm{kg} \cdot \mathrm{h})$ to achieve euglycemia. The serum ammonia was within normal range and $\beta$ hydroxybutyrate/non-esterified fatty acids were low in all patients.

\section{Clinical course}

After a 5-day trial of diazoxide, $6(12 \%)$ patients were responsive while $26(52 \%)$ patients were unresponsive. The mean fasting time was significantly lower in the unresponsive patients $(2.5 \pm 2.4 \mathrm{~h})$ compared with that in the diazoxideresponsive patients $(6 \pm 3.3 \mathrm{~h}, P<0.05)$. During hypoglycemia periods, the serum insulin level was significantly increased in diazoxide-unresponsive patients (mean insulin level, $29.6 \pm 32.7 \mu \mathrm{IU} / \mathrm{ml})$ compared with the diazoxideresponsive patients (mean insulin level, $11.5 \pm 8.6 \mu \mathrm{IU} / \mathrm{ml}$, $P<0.05)$. After given diazoxide, 37(74\%) patients experienced at least one adverse drug reaction (ADR). Eighteen (36\%) patients' responsiveness to diazoxide was unknown due to side effect-related therapy suspension (Fig. 1). Gastrointestinal disturbances, circulatory complications, hypertrichosis was the most commonly observed in $48.4 \%$, $41.9 \%$, and $41.9 \%$ patients respectively.

\section{${ }^{18}$ F-DOPA-PET CT scanning}

${ }^{18} \mathrm{~F}$-DOPA-PET CT scanning revealed that, in the $50 \mathrm{CHI}$ patients, $16(32 \%)$ patients had focal lesion while the other $34(68 \%)$ had diffuse lesion. Among the 16 focal type patients, 1 patient $(6.3 \%)$ was diazoxide responsive while $12(75 \%)$ were unresponsive and three (18.7\%) patients' diazoxideresponsiveness was unknown. Similarly, in 34 patients with diffuse lesion, 14 (41.2\%) were diazoxide-unresponsive while $5(14.7 \%)$ were diazoxide-responsive and $15(44.1 \%)$ patients' diazoxide-responsiveness were unknown (see Fig. 1). 


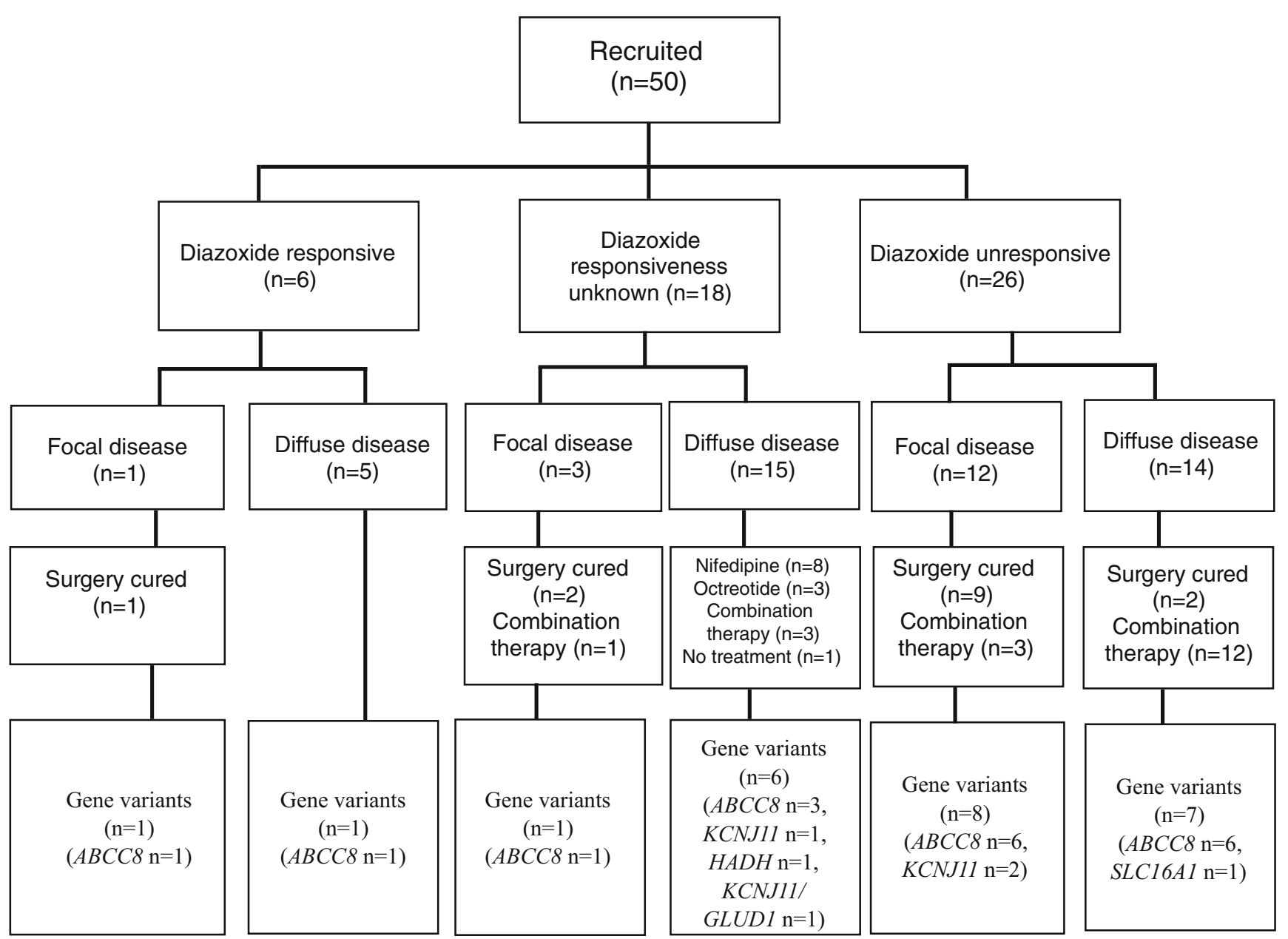

Fig. 1 Summary of clinical course, ${ }^{18}$ F-DOPA-PET CT findings, and genotypes of 50 Chinese patients

Compared with the diffuse-type patients (median age, 13 days; range, after birth to 11 years), the focal-type patients were significantly younger at presentation (median age, 1.5 days; range, $6 \mathrm{~h}$ to 3 months $)(P<0.05)$. The mean fasting time $(2.1$ $\pm 1.5 \mathrm{~h}$ ) of the focal-type patients were significantly shorter than that of the diffuse-type patients $(4.4 \pm 3.6 \mathrm{~h})(P<0.05)$.

\section{Clinical outcome with and without pancreatectomy}

Totally, 14 patients (12 focal-type and 2 diffuse-type) received pancreatectomy. Among them, 2 patients with diffuse lesion and 1 patient with 2 focal lesions received near-total pancreatectomy (Table 1). Eleven patients with focal lesion underwent subtotal pancreatic resection. The resected tissue's histological findings were consistent with the ${ }^{18}$ F-DOPA-PET CT scan results. Under normal feeding, no patient had hypoglycemia after the surgery. Among the 36 nonsurgically treated patients, except one patient with diffuse lesion who only need frequent feeding to achieve euglycemia, 5 patients were controlled with diazoxide, 3 patients using octreotide, 8 patients using nifedipine plus frequent feeding, and 19 patients were in combination therapy with diazoxide, octreotide, and nifedipine, including 4 patients with focal disease on PET CT as the proposal of pancreatectomy was rejected by their parents (Fig. 1).

\section{Genetic analysis}

A total of 31 nucleotide sequence changes within the CHIrelated genes were identified in 24 of 50 (48\%) patients. Most of which involved the $A B C C 8$ and $K C N J 11$ genes $(27 / 31,87.1 \%)$ found in 22 of $50(44 \%)$ patients. Among them, 18 patients $(36 \%)$ harbored $23 A B C C 8$ gene variants with 4 novel (Q289X, Q608X, Q1347X and F1489S) variants. Four patients $(8 \%)$ harbored $4 \mathrm{KCNJ11}$ variants with 2 novel missense variants (G132A, V138E). The other sequence changes were in SLC16Al $(n=1), H A D H(n=2)$, and GLUD1 $(n=1)$. Fifteen of the $23 A B C C 8$ gene variants

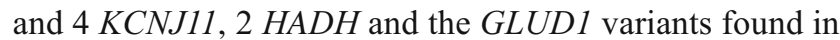
this study were predicted to be diseasing causing by online mutation prediction tools (Table 2 ). The rest variants were predicted to be benign. 
Table 1 Summary of CHI patients who underwent pancreatectomy

\begin{tabular}{|c|c|c|c|c|}
\hline Patient no. & PET CT & Pancreatectomy & Diazoxide responsiveness & Mutation \\
\hline 1 & Focal & Partial (tail, 30\%) & Unresponsive & - \\
\hline 2 & Focal & Partial (tail, 30\%) & Unresponsive & - \\
\hline 3 & Focal & Partial (head, 25\%) & Unresponsive & $A B C C 8$ c. $4039 \mathrm{C}>\mathrm{T}$ p.Q1347X \\
\hline 4 & Focal & Partial (head, 20\%) & Responsive & $A B C C 8$ c.331G > A p.G111R \\
\hline 5 & Focal & Near-total (head and body, 90\%) & Unresponsive & KCNJ11 c.413 T>A p.V138E \\
\hline 6 & Focal & Partial (head, 30\%) & Responsiveness unknown & - \\
\hline 7 & Focal & Partial (body, 50\%) & Unresponsive & ABCC8 c.2691delC p. W898Gfs*5 \\
\hline 8 & Focal & Partial (head, 30\%) & Unresponsive & KCNJ11 c. $602 \mathrm{G}>\mathrm{C}$ p.R201P \\
\hline 9 & Focal & Partial (tail, 40\%) & Unresponsive & - \\
\hline 10 & Focal & Partial (body and tail, 60\%) & Unresponsive & - \\
\hline 11 & Focal & Partial (tail, 25\%) & Responsiveness unknown & $A B C C 8$ c. $.742 \mathrm{C}>$ T p. R248X; c.2690A > T p.D897V \\
\hline 12 & Focal & Partial (body, 50\%) & Unresponsive & ABCC8 c.3124_3126delins13 p.T1042Qfs*75 \\
\hline 13 & Diffuse & Near-total $(90 \%)$ & Unresponsive & - \\
\hline 14 & Diffuse & Near-total $(95 \%)$ & Unresponsive & ABCC8 c.4307G > A p.R1436Q; c.1887_1888delCAinsA \\
\hline
\end{tabular}

Compared with the rest with/without CHI-related mutation (mean age, 248.5 days), the patients with $A B C C 8$ or KCNJ11 mutation were younger at presentation (mean age,
10.8 days for $A B C C 8$ and 0.8 days for $K C N J 11)(P<0.05)$. $9.5 \%$ patients with $A B C C 8 / K C N J 11$ mutation were responsive to diazoxide. However, there was no statistical

Table 2 CHI-related variants found in 50 Chinese patients

\begin{tabular}{|c|c|c|c|c|}
\hline Mutation & PolyPhen-2 & Mutation taster & Previous reported mutation & Age at presentation \\
\hline \multicolumn{5}{|l|}{ ABCC8 } \\
\hline c. $1822 \mathrm{C}>\mathrm{T}$ p.Q608X & - & Disease Causing & Novel & $1 \mathrm{~h}$ \\
\hline c. $4039 \mathrm{C}>\mathrm{T}$ p.Q1347X & - & Disease Causing & Novel & $15 \mathrm{~h}$ \\
\hline c. $4307 \mathrm{G}>$ A p.R1436Q & Probably damaging & Disease Causing & $\mathrm{Y}$ & $30 \mathrm{~min}$ \\
\hline c.1887_1888delCAinsA & - & Disease Causing & $\mathrm{Y}$ & $30 \mathrm{~min}$ \\
\hline c. $1501 \mathrm{G}>$ A p.E501K & Probably damaging & Disease Causing & $\mathrm{Y}$ & 11 days \\
\hline c.331G > A p.G111R & Probably damaging & Disease Causing & $\mathrm{Y}$ & 2 days \\
\hline c.721del p.H241lfs; & - & Disease Causing & $\mathrm{Y}$ & 3 days \\
\hline c.563A > G p.N188S; & Possible damaging & Disease Causing & $\mathrm{Y}$ & 3 days \\
\hline c. 2691 delC p. W898Gfs*5 & - & Disease Causing & $\mathrm{Y}$ & 2 days \\
\hline c. 4466 T > C p.F1489S & Possible damaging & Disease Causing & Novel & 1 day \\
\hline c. $742 \mathrm{C}>\mathrm{T}$ p. R248X & - & Disease Causing & $\mathrm{Y}$ & 1 day \\
\hline c. $2690 \mathrm{~A}>$ T p.D897V & Probably damaging & Disease Causing & $\mathrm{Y}$ & 1 day \\
\hline c. $865 \mathrm{C}>\mathrm{T}$ p.Q289X & - & Disease Causing & Novel & 5 months \\
\hline c.3124_3126delins13 p.T1042Qfs*75 & - & Disease Causing & $\mathrm{Y}$ & $20 \mathrm{~h}$ \\
\hline c. $4532 \mathrm{~T}>\mathrm{C}, \mathrm{p} . \mathrm{I} 1511 \mathrm{~T}$ & Possible damaging & Disease Causing & $\mathrm{Y}$ & $2 \mathrm{~h}$ \\
\hline \multicolumn{5}{|l|}{ KCNJ11 } \\
\hline c.101G > A p.R34H & Probably damaging & Disease Causing & $\mathrm{Y}$ & $1 \mathrm{~h}$ \\
\hline c.413 T>A p.V138E & Possible damaging & Disease Causing & Novel & 1 day \\
\hline c. $602 \mathrm{G}>\mathrm{C}$ p.R201P & Probably damaging & Disease Causing & $\mathrm{Y}$ & 2 days \\
\hline c. $395 \mathrm{G}>$ C p.G132A & Probably damaging & Disease Causing & Novel & $1 \mathrm{~h}$ \\
\hline \multicolumn{5}{|l|}{ GLUD1 } \\
\hline c.1564A > G p.M522 V & Possible damaging & Disease Causing & $\mathrm{Y}$ & $1 \mathrm{~h}$ \\
\hline \multicolumn{5}{|l|}{ HADH } \\
\hline c.29G > C p.R10P & Probably damaging & Disease Causing & $\mathrm{Y}$ & 2 years and 2 months \\
\hline c.89 T > A p.V30E & Probably damaging & Disease Causing & $\mathrm{Y}$ & 2 years and 2 months \\
\hline
\end{tabular}


difference in blood glucose, serum insulin level, and glucose infusion rate between the patients with and without CHI-related mutation.

\section{Discussion}

$\mathrm{CHI}$ is a clinically and genetically heterogeneous disorder with dysregulation of insulin secretion from pancreatic $\beta$ cells. As a national referral center, our patients come from $78.1 \%$ provinces of China. We found that only $12 \% \mathrm{CHI}$ patients were diazoxide side effect-tolerant and responsive and $52.0 \% \mathrm{CHI}$ patients were diazoxide-unresponsive, higher than previously reported of other Chinese patients [7, 26]. Compared with the others, the diazoxide-unresponsive patients showed shorter fasting tolerance time and higher serum insulin level.

Relatively high portion of our patients were intolerant to diazoxide and the therapy was halted in $36 \%$ patients. Gastrointestinal disturbances were the most common, occurred in $48.4 \%$ patients, such as poor appetite, nausea, and vomiting. About $6.5 \%$ patients relied on gastric tube feeding. Though diuretic courses were started with diazoxide in all patients, $41.9 \%$ patients had circulatory complications, such as high heart rate, edema, and fluid retention, especially in the first week after the initiation of diazoxide when intravenous dextrose was still needed. $12.9 \%$ patients had congestive heart failure when combined with infection. Hypertrichosis was noted in $22.6 \%$ patients especially 2-3 months after the diazoxide treatment. Similar situations were found in Japanese patients and Beijing cohort, China [6,7]. After given diazoxide, $30.5 \%$ Japanese patients had adverse drug reaction, including hypertrichosis, edema, anemia, and cardiac failure [6]. However, only $14-18 \%$ persistent hypoglycemia patients were diagnosed with edema after given diazoxide in the USA [8, 10]. Moreover, other adverse drug reactions were less common in Asian patients. For example, neutropenia, thrombocytopenia and hyperuricemia found in $15.6 \%$, $4.7 \%$, and $5.0 \%$ patients in the USA [10], occurred in $1 \%, 0.8 \%$, and $0.5 \%$ Japanese patients respectively [6]. All of these highly suggested different racial susceptibility to diazoxide in Chinese or East Asian populations. Careful surveillance for common adverse effects involving digestive and cardiovascular systems is warranted.

To date, variants in genes, such as $A B C C 8, K C N J 11$, GLUD1, GCK, HADH, SLC16A1, UCP2, HNAA, and $H N F 1 A$ are known to cause CHI. In our study, variants in $\mathrm{CHI}-$ related genes were found in $48 \%$ patients. Potential disease-causing mutations in $A B C C 8 / K C N J 11$ gene were the most common, occurring in $44 \% \mathrm{CHI}$ patients but much less than that in Japanese $(61.3 \%)$ and Korean patients $(82.0 \%)$ $[21,28]$. It was noted that T1042Qfs*75, I1511K, E501K, and G111R in $A B C C 8$ gene and $\mathrm{R} 34 \mathrm{H}$ in KCNJ11 gene reoccurred in patients from different regions of China. Patients with the same mutation shared similar clinical characteristics, suggesting that potential hotspot mutations might existed in Chinese CHI patients. T1042Qfs*75 in ABCC8 gene was found in two patient of this study and two patients in our hospital reported before [4]. The patients with T1042Qfs*75 mutation in $A B C C 8$ gene were diazoxideunresponsive and had diffuse lesion in pancreas. $11511 \mathrm{~K}$ in $A B C C 8$ gene was found in two patients of our study. E501K, G111R in ABCC8 gene and R34H in KCNJ11 gene was found in one of our patients and one reported previously [26]. Both the patients had $11511 \mathrm{~K}$ mutation in $A B C C 8$ gene and the patients with $\mathrm{R} 34 \mathrm{H}$ mutation in $K C N J 11$ gene had diffuse lesion and were diazoxide-responsive. The patients with E501K mutation in $A B C C 8$ gene were diffuse-type and diazoxide-unresponsive. The patients with G111R mutation in $A B C C 8$ gene were diazoxide-responsive but had a focal lesion in pancreas. With the widespread adoption of genetic diagnosis in clinic, more mutational hotspots could be found, which would provide more detailed information to guide the management of $\mathrm{CHI}$ in Chinese patients.

In our study, we discovered 4 novel variants in $A B C C 8$ gene and 2 novel variants in $K C N J 11$ gene. In the 4 novel variants in $A B C C 8$ gene, 3 were nonsense mutation as Q608X, Q1347X, and Q289X, which resulted in an incomplete and usually nonfunctional protein product. The other novel missense variant, F1489S in the $A B C C 8$ gene, was predicted as disease-causing. All four patients with the novel mutation were diazoxide-unresponsive. The patient with Q1347X mutation had a focal lesion and was surgically cured, while the other three patients were diffuse-type and were managed with combined therapy of diazoxide, nifedipine, and octreotide. The other two novel KCNJ11 variants, G132A and V138E, were both predicted as disease-causing. The patient with G132A had a diffuse disease and was controlled by octreotide and nifedipine. However, V138E variant in KCNJ11 gene caused two focal lesions (Fig. 2) in the patient who was cured through near-total pancreatectomy. Pathology results confirmed islet cell adenomatosis in the uncinate process and body of the patient's pancreas.

Apart from the patients with novel mutation, the other patients with $A B C C 8 / K C N J 11$ variants were mostly diazoxide-unresponsive and younger at presentation compared with other forms. $62.5 \%$ of focal-type patients in our study were found to have $A B C C 8 / K C N J 11$ mutation. The findings in our study supported the notion that $\mathrm{CHI}$ patients with $A B C C 8 / K C N J 11$ mutation were more difficult to manage through medical therapy but more likely to be cured through surgery after the historical type determination by ${ }^{18} \mathrm{~F}$-DOPA-PET CT scan. ${ }^{18} \mathrm{~F}$-DOPA-PET CT scan is highly sensitive and specific in helping with differentiating between diffuse and focal form of $\mathrm{CHI}[25,27]$. The 


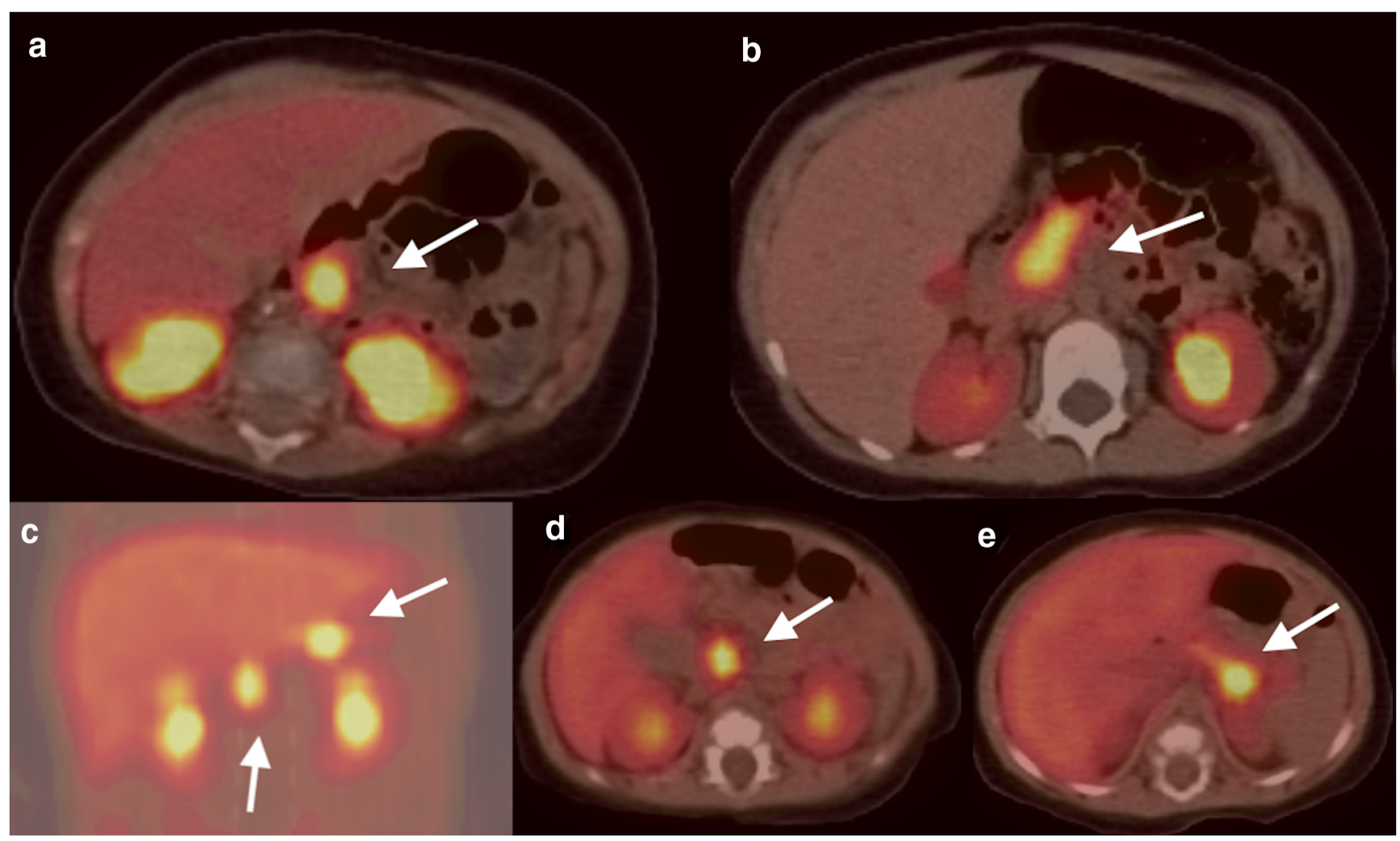

Fig. 2 Typical ${ }^{18}$ F-DOPA-PET CT images in Chinese CHI patients. Focal lesion in the head of the pancreas (a, white arrow); diffuse lesion in the pancreas (b, white arrow); focal lesions both in the head and body of pancreas (c, d, e, case 5, KCNJ11 V138E mutation, white arrow)

complete excision of the lesion, especially the focal lesion, greatly relies on the preoperative ${ }^{18} \mathrm{~F}$-DOPA-PET CT and the intraoperative histological confirmation. Without ${ }^{18} \mathrm{~F}$ DOPA-PET CT scan, the outcome of surgical treatment is uncertain [7]. In all $50 \mathrm{CHI}$ patients of our study, 16 (32\%) patients had focal lesion while $34(68 \%)$ had diffuse subtype, identified by ${ }^{18} \mathrm{~F}$-DOPA-PET CT. After considering the result of ${ }^{18}$ F-DOPA-PET CT scan, 12 patients with focal lesion and 2 patients with diffuse lesion were cured through partial or near-total pancreatectomy (Table 1). The histopathological findings were consistent with the ${ }^{18} \mathrm{~F}$ DOPA-PET CT scan results. Confirmed by histopathologic analysis, the focal lesion percentage of our study is $24 \%$ (12/50), lower than that in the North America report (50.5$52.8 \%)[16,23]$ and that in the UK $(27.8 \%)$ [19], but tremendously increased than that in the previous reports of Chinese surgical patients without ${ }^{18} \mathrm{~F}$-DOPA-PET CT scan which was only around 5.3 to $7.7 \%[17,18]$. In combination with our previous report [29], the local ${ }^{18} \mathrm{~F}$-DOPAPET CT scan is comparable sensitive and specific to findings from other countries [25, 27] and demonstrates remarkable benefits in improving the management of $\mathrm{CHI}$ in China.

In summary, despite the comparable diazoxideunresponsiveness in our patients to that in Caucasian $\mathrm{CHI}$ patients, the high intolerance to diazoxide is evident in
Eastern Asian patients. Hotspot and sporadic novel $A B C C 8$ and KCNJ11 gene mutations are predominantly responsible for Chinese CHI patients. A comprehensive etiological diagnosis using both genetic analysis and ${ }^{18} \mathrm{~F}$ DOPA-PET CT scan will contribute to a better management and prognosis of CHI patients.

Authors' Contributions JN designed the study, collected and interpreted the data, and drafted the manuscript. JG, SR, and YG collected and interpreted the data of 18F DOPA-PET CT. MZ, RC, LX, and ZZ helped with data collection. $\mathrm{KH}$ critically revisited the manuscript. FL designed the study, drafted, and critically revisited the manuscript. All authors gave final approval.

Funding The research was supported by the Shanghai Science and Technology Committee (Grant 15411951700).

\section{Compliance with ethical standards}

All procedures performed in studies involving human participants were in accordance with the ethical standards of the institutional and/or national research committee and with the 1964 Helsinki declaration and its later amendments or comparable ethical standards.

Conflict of interest The authors declare that they have no conflict of interest.

Informed consent Infants whose parents gave informed written consent were recruited. 
Open Access This article is distributed under the terms of the Creative Commons Attribution 4.0 International License (http:// creativecommons.org/licenses/by/4.0/), which permits unrestricted use, distribution, and reproduction in any medium, provided you give appropriate credit to the original author(s) and the source, provide a link to the Creative Commons license, and indicate if changes were made.

\section{References}

1. Adzick NS, Thornton PS, Stanley CA, Kaye RD, Ruchelli E (2004) A multidisciplinary approach to the focal form of congenital hyperinsulinism leads to successful treatment by partial pancreatectomy. J Pediatr Surg 39:270-275

2. Arya VB, Guemes M, Nessa A, Alam S, Shah P, Gilbert C, Senniappan S, Flanagan SE, Ellard S, Hussain K (2014) Clinical and histological heterogeneity of congenital hyperinsulinism due to paternally inherited heterozygous $\mathrm{ABCC} 8 / \mathrm{KCNJ} 11$ mutations. Eur J Endocrinol 171:685-695

3. de Lonlay P, Fournet JC, Rahier J, Gross-Morand MS, PoggiTravert F, Foussier V, Bonnefont JP, Brusset MC, Brunelle F, Robert JJ, Nihoul-Fékété C, Saudubray JM, Junien C (1997) Somatic deletion of the imprinted $11 \mathrm{p} 15$ region in sporadic persistent hyperinsulinemic hypoglycemia of infancy is specific of focal adenomatous hyperplasia and endorses partial pancreatectomy. J Clin Invest 100:802-807

4. Fan ZC, Ni JW, Yang L, Hu LY, Ma SM, Mei M, Sun BJ, Wang HJ, Zhou WH (2015) Uncovering the molecular pathogenesis of congenital hyperinsulinism by panel gene sequencing in 32 Chinese patients. Mol Genet Genomic Med 3:526-536

5. Fékété CN, de Lonlay P, Jaubert F, Rahier J, Brunelle F, Saudubray JM (2004) The surgical management of congenital hyperinsulinemic hypoglycemia in infancy. J Pediatr Surg 39: 267-269

6. Fukutomi M, Shimodera M, Maeda Y, Iwakura M, Hara M (2018) Safety and effectiveness, including intelligence prognosis, of diazoxide in pediatric patients with hyperinsulinemic hypoglycemia: special survey in Japan (long-term, all-case survey). Clin Pediatr Endocrinol 27:131-143

7. Gong C, Huang S, Su C, Qi Z, Liu F, Wu D, Cao B, Gu Y, Li W, Liang X, Liu M (2016) Congenital hyperinsulinism in Chinese patients: 5-yr treatment outcome of 95 clinical cases with genetic analysis of 55 cases. Pediatr Diabetes 17:227-234

8. Gray KD, Dudash K, Escobar C, Freel C, Harrison T, McMillan C, Puia-Dumitrescu M, Cotten CM, Benjamin R, Clark RH, Benjamin DK Jr, Greenberg RG, Best Pharmaceuticals for Children ActPediatric Trials Network Steering Committee (2018) Prevalence and safety of diazoxide in the neonatal intensive care unit. $\mathrm{J}$ Perinatol 38:1496-1502

9. Güemes M, Hussain K (2015) Hyperinsulinemic hypoglycemia. Pediatr Clin N Am 62:1017-1036

10. Herrera A, Vajravelu ME, Givler S, Mitteer L, Avitabile CM, Lord K, De León DD (2018) Prevalence of adverse events in children with congenital hyperinsulinism treated with diazoxide. J Clin Endocrinol Metab 103:4365-4372

11. Hussain K (2008) Diagnosis and management of hyperinsulinaemic hypoglycaemia of infancy. Horm Res 69:2-13

12. Hussain K, Seppänen M, Näntö-Salonen K, Adzick NS, Stanley CA, Thornton P, Minn H (2006) The diagnosis of ectopic focal hyperinsulinism of infancy with [18F]-dopa positron emission tomography. J Clin Endocrinol Metab 91:2839-2842
13. Ismail D, Hussain K (2010) Role of 18F-DOPA PET/CT imaging in congenital hyperinsulinism. Rev Endocr Metab Disord 11:165-169

14. Kapoor RR, Flanagan SE, James C, Shield J, Ellard S, Hussain K (2009) Hyperinsulinaemic hypoglycaemia. Arch Dis Child 94:450 457

15. Kapoor RR, Flanagan SE, Arya VB, Shield JP, Ellard S, Hussain K (2013) Clinical and molecular characterisation of 300 patients with congenital hyperinsulinism. Eur J Endocrinol 168:557-564

16. Laje P, States LJ, Zhuang H, Becker SA, Palladino AA, Stanley CA, Adzick NS (2013) Accuracy of PET/CT scan in the diagnosis of the focal form of congenital hyperinsulinism. J Pediatr Surg 48(2):388-393

17. Lee CT, Liu SY, Tung YC, Chiu PC, Wu MZ, Tsai WY (2016) Clinical characteristics and long-term outcome of Taiwanese children with congenital hyperinsulinism. J Formos Med Assoc 115: 306-310

18. Li J, Ma Y, Lv M, Zhou J, Liu B, Dong K, Xiao X, Chen L (2015) Persistent hyperinsulinemic hypoglycemia of infancy: a clinical and pathological study of 19 cases in a single institution. Int J Clin Exp Pathol 8:14417-14424

19. Meintjes M, Endozo R, Dickson J, Erlandsson K, Hussain K, Townsend C, Menezes L, Bomanji J (2013) 18F-DOPA PET and enhanced CT imaging for congenital hyperinsulinism: initial UK experience from a technologist's perspective. Nucl Med Commun 34:601-608

20. Otonkoski T, Näntö-Salonen K, Seppänen M, Veijola R, Huopio H, Hussain K, Tapanainen P, Eskola O, Parkkola R, Ekström K, Guiot Y, Rahier J, Laakso M, Rintala R, Nuutila P, Minn H (2006) Noninvasive diagnosis of focal hyperinsulinism of infancy with [18F]-DOPA positron emission tomography. Diabetes 55:13-18

21. Park SE, Flanagan SE, Hussain K, Ellard S, Shin CH, Yang SW (2011) Characterization of ABCC8 and KCNJ11 gene mutations and phenotypes in Korean patients with congenital hyperinsulinism. Eur J Endocrinol 164:919-926

22. Ribeiro MJ, De Lonlay P, Delzescaux T, Boddaert N, Jaubert F, Bourgeois S, Dollé F, Nihoul-Fékété C, Syrota A, Brunelle F (2005) Characterization of hyperinsulinism in infancy assessed with PET and 18F-fluoro-L-DOPA. J Nucl Med 46:560-566

23. Snider KE, Becker S, Boyajian L, Shyng SL, MacMullen C, Hughes N, Ganapathy K, Bhatti T, Stanley CA, Ganguly A (2013) Genotype and phenotype correlations in 417 children with congenital hyperinsulinism. J Clin Endocrinol Metab 98:E355E363

24. Stanley CA, Thornton PS, Ganguly A, MacMullen C, Underwood P, Bhatia P, Steinkrauss L, Wanner L, Kaye R, Ruchelli E, Suchi M, Adzick NS (2004) Preoperative evaluation of infants with focal or diffuse congenital hyperinsulinism by intravenous acute insulin response tests and selective pancreatic arterial calcium stimulation. J Clin Endocrinol Metab 89:288-296

25. Treglia G, Mirk P, Giordano A, Rufini V (2012) Diagnostic performance of fluorine-18-dihydroxyphenylalanine positron emission tomography in diagnosing and localizing the focal form of congenital hyperinsulinism: a meta-analysis. Pediatr Radiol 42:1372-1379

26. Wang WY, Sun Y, Zhao WT, Wu T, Wang L, Yuan TM, Yu HM (2017) Congenital hyperinsulinism in China: a review of Chinese literature over the past 15 years. J Clin Res Pediatr Endocrinol 9: 194-201

27. Yang J, Hao R, Zhu X (2013) Diagnostic role of $18 \mathrm{~F}$ dihydroxyphenylalanine positron emission tomography in patients 
with congenital hyperinsulinism: a meta-analysis. Nucl Med Commun 34:347-353

28. Yorifuji T, Kawakita R, Nagai S, Sugimine A, Doi H, Nomura A, Masue M, Nishibori H, Yoshizawa A, Okamoto S, Doi R, Uemoto S, Nagasaka H (2011) Molecular and clinical analysis of Japanese patients with persistent congenital hyperinsulinism: predominance of paternally inherited monoallelic mutations in the KATP channel genes. J Clin Endocrinol Metab 96:E141-E145

29. Zhang MY, Ge JJ, Pei Z, Dong KR, Chen L, Wang X, Zhang ZW, Li XJ, Xi L, Cheng RQ, Lu GP, Guan YH, Luo FH (2017)
Feasibility of domestic (18)F-DOPA PET/CT scanning in the differential diagnosis of pancreatic lesions in children with hyperinsulinemic hypoglycemia. Zhonghua Er Ke Za Zhi 55:785789

Publisher's note Springer Nature remains neutral with regard to jurisdictional claims in published maps and institutional affiliations. 